\title{
School on Climate and Environmental Modelling in the West African Region
}

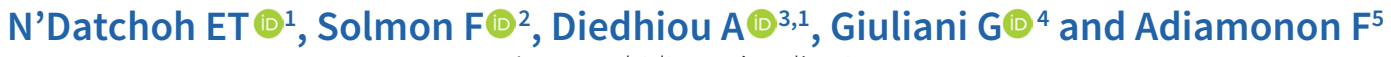 \\ ${ }^{1} U F H B$, Abidjan, Côte d'Ivoire \\ ¿Laboratoire d'Aérologie, Toulouse, France \\ ${ }^{3}$ Univ. Grenoble Alpes, IRD, CNRS, Grenoble - INP, IGE, Grenoble, France \\ ${ }^{4}$ ICTP, Trieste, Italy \\ ${ }^{5}$ ATOS, Abidjan, Côte d'Ivoire
}

https://doi.org/10.17159/caj/2019/29/2.7594

The West African climate is characterized by complex atmospheric dynamics and growing anthropogenic pressures which when its combined with climate change and variability, lead to many environmental impacts. Regional climate models allowing coupling with oceans, surface hydrology, atmospheric chemistry and biogeochemical cycles are appropriate for such complex processes investigation. Therefore, regional climate models offer interesting frameworks for climate impact assessments over West Africa. However, these models complexity require high computing power and appropriate knowledge.

An international workshop on climate and environmental modelling was held from March 11th - 15th at the Pole Scientifique et d'Innovation (PSI) of the University Félix Houphouet-Boigny (Campus of Bingerville, Abidjan, Côte d'Ivoire). This international workshop led by the Numerical Simulation Pole on "Climate and Sustainable Development" was co-organised by the International Centre for Theoretical Physic (ICTP), The Ministry of High Education and Scientific Research of Cote d'Ivoire, in collaboration with Institute of Research and development (IRD), the Centre National de Recherche Scientifique(CNRS) of France, ATOS, WASCAL and the African Centre of Excellence on "Climate Change, Biodiversity and Sustainable Agriculture" (CEA-CBAD). The workshop convened about 50 participants from West Africa, Cameroon and South Africa.

The main objective of the workshop was the reinforcement of the regional climate modelling capacities for a better understanding of local and regional climate process associated with climate change and variability as well as different related impacts.

Specific objectives covered by the workshop were:

- $\quad$ introducing basis of regional climate and earth system modelling;

- $\quad$ Strengthening the expertise of national teams working on regional climate models and their environmental impacts (air quality, agriculture, water resources, health...).

- Reinforcing local and regional interdisciplinary platforms to foster integrated regional climate modelling studies and their applications;

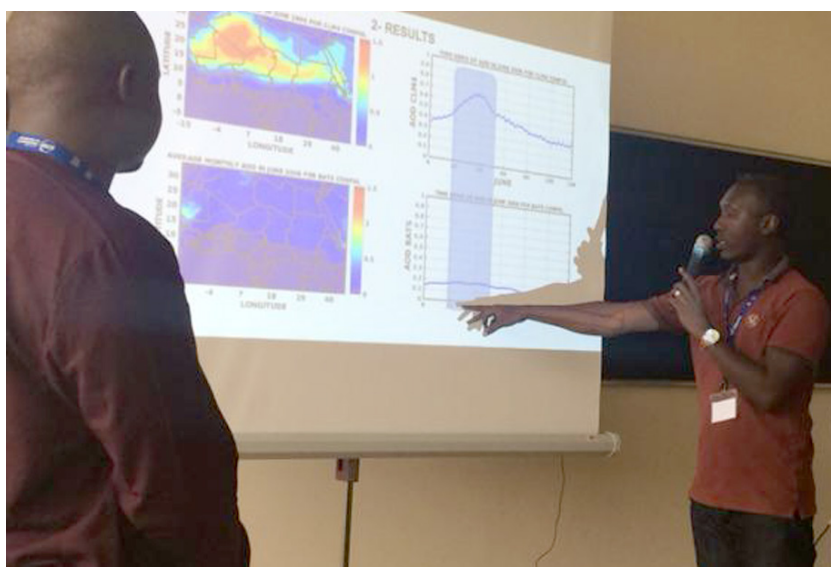

Participants presenting their "small project" results on 15 March 2019

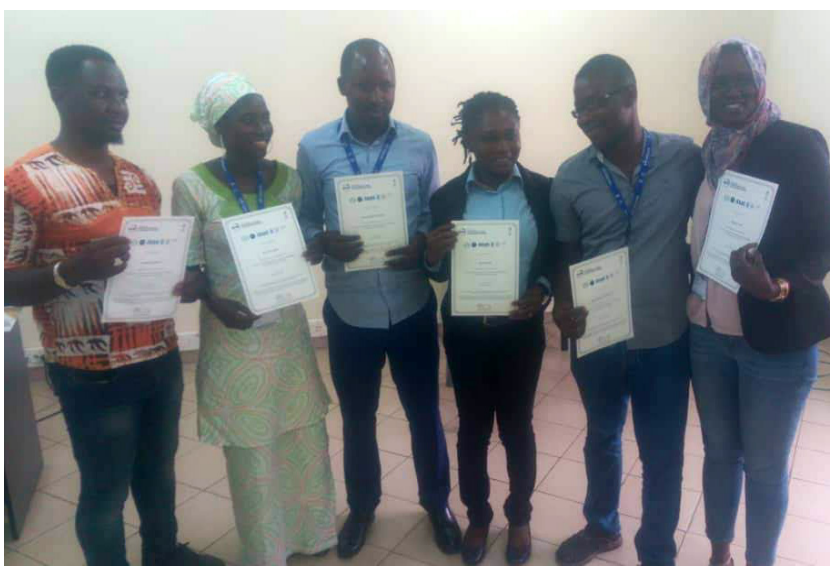

Some participants with their training certificates

- $\quad$ Proposing extensive hands-on regional climate and Earth system modelling sessions using HPC facilities;

- $\quad$ Showing examples of climate and earth system studies over sub-Saharan Africa

- Building a network of African scientists contributing to CORDEX-Africa initiative and fully involved in the future CORDEX Flagship Pilot Studies envisionned for West and Central Africa. 
This workshop was divided into theoretical and practical sessions. Models fundamental basics such as atmospheric dynamics and numerical representation, parametrisation, hydrostatic assumption, resolution (temporal, spatial and vertical), aerosol interactions with African climate as well as simulated PM2.5 surface concentrations and their health impacts were discussed. These models fundamental basements were discussed by prominent scientists:

- Dr Hubert Gallée, Université Grenoble Alpes, IGE, Grenoble (France)

- $\quad$ Dr Fabien Solmon, LA, Toulouse (France) and ICTP

- Model developer Mr Graziano Guiliani, ICTP, Trieste (Italy)

- Dr Bamba M. Sylla, WASCAL Competence Centre, Ougadougou (Burkina Faso)

- Dr N'Datchoh E. Toure, UFHB, Abidjan (Cote d'Ivoire)

Then, practical sessions allowed participants to run their own "small projects" using regional modelling tools such as MAR and RegCM4 on the Ivorian supercomputer named WOMBELE. With its peak performance of 322 teraflops and storage capacity of $5 \mathrm{~PB}$, it is the second supercomputer in Africa. Côte d'Ivoire is the first country in West Africa to set up a national supercomputing centre with the purpose of sharing computing systems between universities and industrials. Atos' Center for Excellence in Parallel Programming supports the Côte d'Ivoire Ministry in their ambitious project with two concurrent actions:

- By delivering organisational recommendations for setting up an efficient operational structure and a balanced decisional system for sharing computing resources between national research communities.

- $\quad$ Setting up application knowledge transfer to the national research ecosystem,

so as to push national excellence to a level recognized by the HPC community. Many actions are scheduled such as regular trainings, workshops, and creating HPC academic training.

On the Friday 15th March, participants presented their results from numerical experiments for examples reforestation of Sahara into Savana and assessment of the associated impact on West African Monsoon system, high resolution simulation of a convective system over the West African region, simulation of dust outbreaks and climatic impacts on the West African region, model intercomparison between MAR and RegCM4 regional climate models.

The final discussion rose the issues about how to optimally invest in research infrastructure and scientist education in Africa for tackling numerical studies on climate and impacts.

\section{Dedication}

This paper is dedicated to the memory of late Prof Abdourahamane Konare who coordinated the project of the Ivorian HPC with the ambition to offer a powerful numerical platform and research environment to all African scientists who need more computational resources to make their research work.

\section{Acknowledgement}

Special thanks to ICTP, DGRI, UFHB, IRD, LA, ATOS, IGE, WASCAL, CEA-CCBAD for the financial support which allowed the organisation of the workshop. 